\title{
A descriptive Study on Uterine Compression U-sutures to Control Postpartum Hemorrhage with fertility Preservation: A Simple and Effective Technique
}

\author{
Mst. Rokeya Khatun ${ }^{1}$, Jesmin Shahela ${ }^{2}$
}

\begin{abstract}
Objective: This study evaluated the effectiveness of a modified U-suturing technique in effecting uterine compression in patients with atonic primary postpartum hemorrhage (PPPH), which does not respond to manual compression or drugs.
\end{abstract}

Method: We retrospectively reviewed the charts of all patients who delivered between 2013 and 2015 at Gynae \& Obstetrics Department of Rajshahi Medical College Hospital and who underwent uterine compression sutures for PPPH and results of a follow-up and questionnaire were evaluated and our experience with this method was reviewed.

Results: Fifty two women had uterine compression U sutures for P PPH. The mean age of the patients was $24 \pm 2.2$ years. The mean gestational age at delivery was $38.2 \pm 2.3$ weeks, and the average estimated blood loss was $2.3 \pm 2.1 \mathrm{~L}$. The mean procedure time to perform the uterine compression $U$ sutures was $11.5 \pm 2.8$ minutes. None of the 52 patients required hysterectomy.

Conclusion: Uterine compression U-sutures technique is an easily and rapidly applied, effective, simple, safe \& life saving method for the treatment of PPPH, thus avoiding hyterectomy and preserving potential fertility.

TAJ 2013; 26: 67-73

\section{Introduction}

Worldwide more than 125,000 women die of postpartum hemorrhage (PPH) each year ${ }^{1}$. PPH complicates approximately $3.7 \%$ of vaginal and $6.4 \%$ of caesarean delivery ${ }^{2}$. PPH is also a major cause of maternal morbidity, with sequel such as hemodynamic shock, renal failure, acute respiratory distress syndrome, coagulopathy, and Sheehan's syndrome. PPH is one of the top five causes of maternal mortality in both developed and developing countries, although the absolute risk of death is much lower in the former than the latter (1 in 100,000 versus 1 in 1000 births) ${ }^{3}$.
$\mathrm{PPH}$ is defined as estimated blood loss of $\geq 500$ $\mathrm{mL}$ after vaginal delivery or $\geq 1000 \mathrm{~mL}$ after cesarean section $^{3,4}$. Another definition of PPH is a reduction in the patient's hematocrit level of more than $10 \%$ compared with the prenatal value or blood loss causing hemodynamic instability of sufficient degree to require blood transfusion ${ }^{5,6}$. Uterine atony is the most common cause of $\mathrm{PPH}$, accounting for $80 \%$ of $\mathrm{PPH}$ cases $^{7,8}$. Other causes include trauma-related bleeding that can be due to lacerations (perineal, vaginal, cervical, uterine), incisions (hysterectomy, episiotomy), or uterine rupture. Lacerations of the birth canal and uterus are more common after instrumental delivery.

\footnotetext{
${ }^{1}$ Asst. Professor, Dept of Gynaecology and Obstetrics, Rajshahi Medical College Hospital, Rajshahi.

${ }^{2}$ Associate Professor, Department of Gynae \& Obstetrics, Rajshahi Medical College \& Hospital, Rajshahi.
} 
Acquired and congenital bleeding diatheses may be associated with thrombocytopenia and/or haemostatic defects (e.g., HELLP syndrome [haemolysis, elevated liver enzymes, and low platelet count], abruptio placentae, fetal demise, amniotic fluid embolism, andsepsis). Coagulopathy of massive blood loss may develop in women with severe hemorrhage.

The treatment of $\mathrm{PPH}$ depends on the underlying cause and includes both routine prophylactic measures during the time of delivery and additional treatment in cases of PPH. Prophylactic strategies, including the administration of oxytocin after delivery, have been shown to reduce the incidence of PPH from as much as $18 \%$ to around 5 to $8 \%{ }^{9}$. Treatment of $\mathrm{PPH}$ due to uterine atony comprises medical and noninvasive treatment such as bimanual compression of the uterus, uterotonic medications, and placement of intrauterine balloon. Failure of medical treatment occurs in less than $1 \%$ of patients ${ }^{10}$. Hysterectomy is considered to be the final option when all conservative and surgical treatments fail. Postpartum hysterectomy not only leads to infertility but may also be associated with surgical difficulties and further complications including injury to adjacent organs such as bladder and ureters and infection.

Surgical techniques that are aimed to preserve the uterus have been developed over the past 15 years. In 1997 Christopher B-Lynch devised an innovative technique to treat uterine atony where a continuous suture was used to envelop and mechanically compress the uterus in an attempt to avoid hystrectomy ${ }^{11}$. Hayman suture, the modification of B-Lynch suture, offers the potential advantage that it can be applied faster and easier, avoiding the performance of a lower segment hysterectomy, when $\mathrm{PPH}$ follows a vaginal delivery ${ }^{12}$. Uterine compression sutures have been reported as an effective method in treating $\mathrm{PPH}$ and thus avoiding hysterectomy. However, the reported experience with this method is limited. In the present study, we describe our experience over the past 36 months in using modified U-suturing methods to treat P PPH and evaluate the role of these sutures in treating patients with failed conservative treatment.

\section{Materials and methods}

A retrospective study of all women who delivered between January 2013 and December, 2015 was collected from our departmental database. Primary $\mathrm{PPH}$ is defined as a blood loss of more than 500 $\mathrm{ml}$ at or within 24 hours of delivery. There were a total of 16,200 deliveries during this period, with primary $\mathrm{PPH}$ occurring in 894 of these cases. Blood loss of $500 \mathrm{ml}$ or more was determined by visual inspection by the attending obstetrician which was a subjective judgment. Out of the 894 cases of PPH, 654 (73.19\%) cases were of PPH due to uterine atony. Uterine atony was determined by abdominal palpation of uterus. In Atonic PPH uterus is soft in contrast to traumatic PPH where uterus is firm, followed by bimanual examination under anesthesia. Additionally before proceeding for $U$ suture, per vaginal examination was done under anesthesia to rule out evidence of trauma. Patient's record was also examined to rule out any pre existent coagulopathy.

The modify U suture procedure was performed in 52 cases only after uterine atony did not respond to measures such as

(i) manual compression and uterine massage;

(ii) Tab. Misoprostol $80 \mu$ g per rectally single dose.

(iii) oxytocin treatment (10 u after delivery and 30 $\mathrm{u}$ in $500 \mathrm{ml}$ of $0.9 \%$ sodium chloride solution infused at a rate of $124 \mathrm{ml} / \mathrm{h}$ );

(iv) Inj. Ergometrin 2 amp I/M single dose. Out of these 52 cases, 45 cases were delivered in our Institute and 7 cases were referred from other hospitals. The need for hysterectomy was avoided in all the cases. It is believed that the ideal suture should be strong, monofilament (to minimize possible trauma to the friable tissue of the atonic uterus), quickly absorbed, and mounted on a large curved or on a straight needle. Ideally the suture needs to maintain the tensile strength for 48-72 hours. In our series of 52 cases the procedure was done with Vicryl No-1 (Polyglactin) in all the cases. 
The procedure for modify $U$ suture technique was as follows:

1. The patient was given appropriate anesthesia and catheterized.

2. The abdomen was opened by an appropriate sized incision or if the patient had a caesarean section the same incision.

3. On entering the abdomen the uterus was exteriorized and rechecked to identify any bleeding point. If bleeding was diffuse as in uterine atony and coagulopathy or profuse placental bleeding where no obvious bleeding point is observed, then bimanual compression was first applied to assess the potential chances of success of the $U$ suturing technique. The vagina was swabbed to confirm adequate control of the bleeding.

4. If the vaginal bleeding was controlled, An absorbable Vicryl 0 thread whose curve had been straightened manually were used for suturing. To perform an interrupted single U-suture, the needle was inserted at the ventral uterine wall, led through the posterior wall and then passed back to the ventral wall where the thread was joined with a flat double knot (Fig. 1a and b). While the lead surgeon was tying the suture, the assisting surgeon performed bi-manual uterine compression. The number of sutures required depended on the size of the uterus and the persistence of bleeding. In general, we inserted 6-16 U-sutures in horizontal rows along the uterus (Fig. 2), starting at the fundus and ending at the cervix. Thus, approximately 2-4 cm of tissue was compressed within each suture. Antibiotics were given postoperatively for at least 5 days. Figure 1 shows the photograph of modify $U$ suture taken in a case of atonic PPPH.

Post procedure the patients were discharged after seven days. At the time of hospital stay all patients were examined daily by the Obstetrician's team on daily round. After that patients were called on the follow-up initially weekly for first six weeks and later monthly up to six months. In the follow-up visits women were interviewed and examined for any complications and side-effects by obstetricians. No deliberate follow-up was made later than six months.

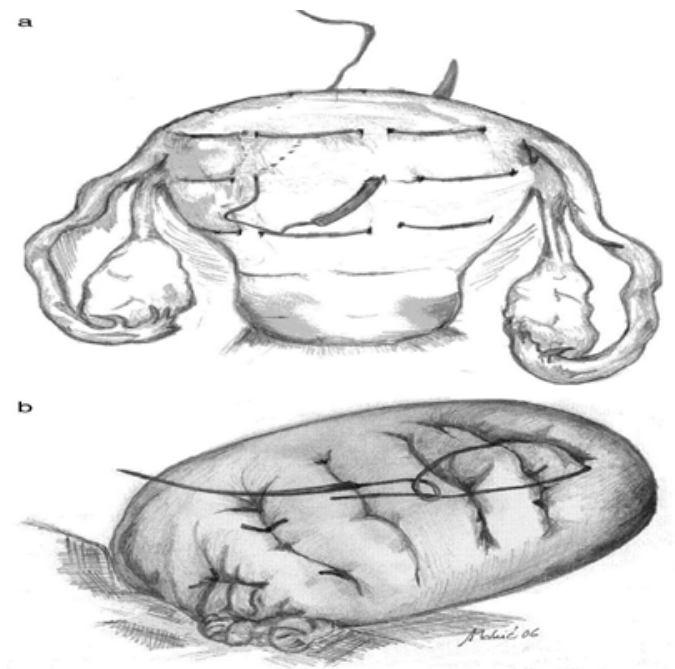

Fig. 1

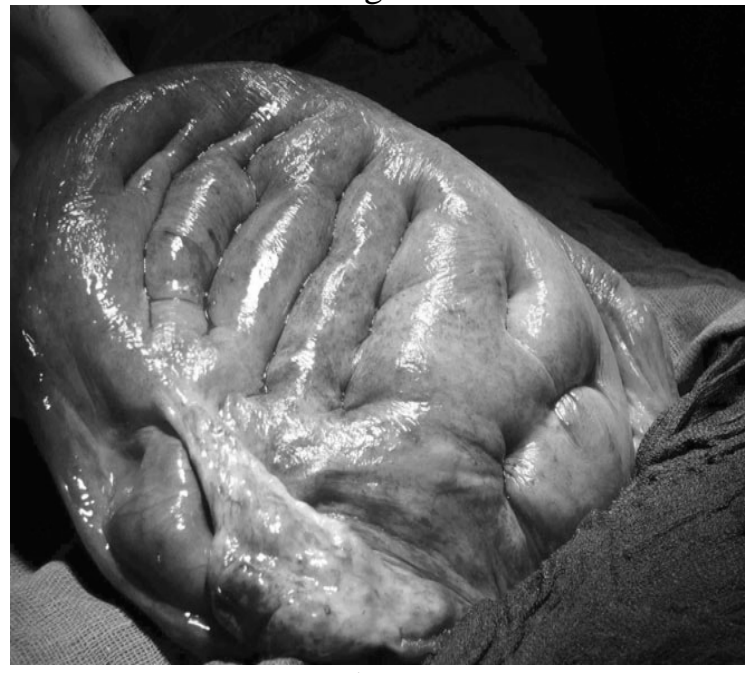

Fig. 2

\section{Results}

Maternal characteristics are summarized in Table 1. The mean age of the women was $24 \pm 2.2$ years (range 16 to 37years). Mean hemoglobin concentration before delivery was $11.45 \mathrm{~g} / \mathrm{dL}$ and after delivery was $7.8 \mathrm{~g} / \mathrm{dL}$. Gestational weeks of women was in most of the pregnancy were at term. Mode of delivery of women was in whom $U$ suture was applied, 42 were delivered by LSCS. Numbers of primary cases were $45 \& 7$ patients out of 52 were referred from outside. Table 2 showing the interval between application of modify $U$ suture from the time of detecting the $\mathrm{PPPH}$. Most $(73.08 \%)$ of the intervention was done within 30 minutes of onset of PPPH. 
TAJ June-December 2013; Volume 26

Table 1: Maternal Demographics and Characteristics

\begin{tabular}{|c|c|c|}
\hline \multicolumn{3}{|c|}{ Primary Post partum hemorrhage $(n=654)$} \\
\hline Paramete & $\begin{array}{l}\text { Those who undergo modify U suture } \\
\text { for uterine atony }(n=52) \text { (Percentage) }\end{array}$ & $\begin{array}{l}\text { Those who undergo other method } \\
\text { (traditional approach) for uterine atony } \\
\text { (n=602) (Percentage) }\end{array}$ \\
\hline \multicolumn{3}{|l|}{ Age } \\
\hline$<20$ years & $5(9.61 \%)$ & $183(30.39 \%)$ \\
\hline 20 to 25years & $28(53.84 \%)$ & $205(34.05 \%)$ \\
\hline 26 to 30 years & $13(25.00 \%)$ & $155(25.74 \%)$ \\
\hline$>30$ years & $6(11.53 \%)$ & $59(9.80 \%)$ \\
\hline \multicolumn{3}{|l|}{ Parity } \\
\hline Primi gravida & $5(9.61 \%)$ & $153(25.41 \%)$ \\
\hline Second gravida & $34(65.38 \%)$ & $283(47.00 \%)$ \\
\hline Third gravida & $8(15.38 \%)$ & $102(16.94 \%)$ \\
\hline More than three gravida & $5(9.61 \%)$ & $64(10.63 \%)$ \\
\hline \multicolumn{3}{|l|}{ Period of gestation } \\
\hline Term & $41(78.84 \%)$ & $536(89.03 \%)$ \\
\hline Pre-term & $11(21.16 \%)$ & $66(10.97 \%)$ \\
\hline \multicolumn{3}{|l|}{ Mode of delivery } \\
\hline Lower Segment Cesarean Section & $42(80.76 \%)$ & $137(22.75 \%)$ \\
\hline Vaginal delivery & $10(19.24 \%)$ & $465(77.25 \%)$ \\
\hline \multicolumn{3}{|l|}{ Place of delivery } \\
\hline Primary cases delivered in $\mathrm{RMCH}$ & $45(86.53 \%)$ & $361(59.96 \%)$ \\
\hline Referred from outside & $7(13.47 \%)$ & $241(40.04)$ \\
\hline
\end{tabular}

Table 1 Modify U suture application

\begin{tabular}{lcc}
\hline Parameter & Number $(\mathrm{n}=52)$ & Percentage \\
\hline Time taken to apply the modify U suture from the time of detecting the PPH & 4 & $7.69 \%$ \\
$<15$ minutes & 38 & $73.08 \%$ \\
16 to 30 minutes & 10 & $19.23 \%$ \\
$>30$ minutes & & 10 \\
\hline
\end{tabular}

Table 3. Follow up of patient's with modify U suture .

\begin{tabular}{lcc}
\hline Period of follow-up & Number (n=52) & Percentage \\
\hline Followed-up to seven days & 52 & $100 \%$ \\
Followed-up to six weeks & 44 & $84.61 \%$ \\
Followed-up to six months & 42 & $80.76 \%$ \\
Women coming with subsequent pregnancy at the Institute & 2 & $3.84 \%$ \\
Women with subsequent pregnancy for regular ante-natal care at the Institute & 2 & $3.84 \%$ \\
Women with subsequent pregnancy delivered at the Institute & 2 & $3.84 \%$ \\
\hline
\end{tabular}

Follow up of the patients was as per Table 3. Out of total patients all were followed up to seven days, 44 were followed up to six weeks and 42 were followed up to six months. Rest of the patients stopped coming for follow-up visits and could not be traced hence their outcome was not known. Also important is that out of the 52 initial patients, 2 became pregnant and came to the Institute, both of them delivered subsequently in the Institute in follow up till December 2015. Those women who might have become pregnant and visited other hospitals could not be traced. All the 52 cases in the study had evidence of uterine atony which responded poorly to conventional uterotonics, bleeding was controlled in all the cases with U sutures thus averting hysterectomy.

\section{Discussion}

Till now PPH is a common obstetric emergency which need emergency hysterectomy in patients not responding to traditional treatment. Surgical methods of controlling uterine bleeding by inserting compression sutures have been developed to reduce the incidence of emergency 
hysterectomy and to preserve fertility in these patients. In this study, we have evaluated a Usuture technique for achieving uterine compression in PPH. The U-sutures were easy to perform during emergency conditions; they are a safe and relatively inexpensive procedure. Furthermore, the technique enabled us to avoid emergency peripartum hysterectomy in all patients and thus preserve their fertility and obviate any other surgical complications of hysterectomy in these circumstances.

There have been isolated reports of adverse consequences after B-Lynch application. In 2004, Grotegut et al reported one case of erosion of a BLynch suture through the uterine wall, in a 19 year old primigravida ${ }^{13}$. Partial ischemic necrosis of the uterus occurring 24 hours after the procedure has also been reported in a 26-year old primi gravida who underwent an emergency caesarean section for fetal distress followed by B-Lynch suture ${ }^{14}$. The effect of the erosion on future fertility and labor remains unknown. Despite this, many patients on long term follow up have demonstrated resumption of normal menstrual periods and normal reproductive health ${ }^{15}$.

Long term complications such as formation of bowel adhesion have also been reported ${ }^{16}$. Comparing B-Lynch suture with Hayman suture, B-Lynch is time consuming and there is bleeding from uterus due to multiple bites. Uterine opening is avoided with Hayman suture. Cervical stenosis, haematometra, partial necrosis and sloughing of uterine wall have been documented by various surgeons as a complication of original B-Lynch suture technique. Since modified B-Lynch brace sutures is a newer technique, and most of the studies are based on case reports and are without proper controlled studies, more controlled studies are required before it is accepted as a standard method $^{17}$.

Another study by Ghodke et al, 2008 have reported no mortality after B-Lynch suture but minor complications like fever (5 out of 31) and wound gap (3 out of 31) was reported, though the period of followup was not specified in the study $^{17}$. Study by Fatima N et al, 2010 from
Pakistan for effectiveness of combine B-Lynch brace suture plus uterine packing in $\mathrm{PPH}$ in 22 cases reported zero infection rate and two (9.1\%) cases of secondary PPH requiring Hysterectomy ${ }^{18}$. One more study from Pakistan also showed failure rate of $6.6 \%$ (1 out of 15 needing hysterectomy) with B-Lynch suture technique ${ }^{19}$.

After revew of several article on uterine compression suture, we introduced the U-suture method of uterine compression in 2013, since then we have not had to perform any emergency hysterectomies because of primary $\mathrm{PPH}$, nor have we encountered any complications related to compression suturing. Furthermore, clinical \& ultrasonographic follow-up excluded possible complications such as intrauterine synechia, adhesions, irregular menstruation or menstruationassociated pain symptoms and reduced fertility. These results confirm those in a case report describing a 12-suture, uterus penetrating technique and also the work of Ferguson et $\mathrm{al}^{20}$, who followed up two patients who had undergone the B-Lynch suturing procedure and found no defects of the uterine cavity after performing magnetic resonance imaging and hysterosalpingography ${ }^{21}$. At followup in our patients, none had any symptoms that might have been linked to the procedure and there were no clinical symptoms or signs suggesting intra-abdominal adhesions. Therefore we did not undertake control laparoscopies to rule out adhesions on the anterior wall of the uterus where multiple knots had been placed. Compared to other described compression sutures we postulate that, the interrupted single U-sutures (from 6 to 16 in numbers) provide more effective compression during uterine involution because several areas are compacted and if one suture fails, the remainder is not affected. (Fig. 2). Further investigations will provide information on the rate of vascular ligations, hysterectomies and other complications. In treating the women describe here, we experienced a learning curve. After standard treatment for uterine atony had failed, the time span we allowed for trying conservative treatments such as manual compression and drugs before applying the U-sutures decreased, and therefore 
the surgical operation time and blood loss decreased consecutively. The prognosis for these patients depends on a number of factors, but prompt diagnosis and speedy treatment are essential. Compared with the technique described by Pereira et $\mathrm{al}^{22}$. Our procedure for inserting Usutures is fast and very easy to remember and to perform in an emergency situation. We do not believe that complicated instructions for uterus cavity sparing sutures are feasible or essential in an emergency setting. The B-Lynch, Hayman, Bhal, Nelson and Malibary sutures described earlier compress the uterus like a brace; failure to preserve the uterus, suture erosion, and partial and total uterine necrosis have been reported after these methods ${ }^{13,14,25}$. In addition, Cho's square suture was related to pyometria, synechia and Ashermann's syndrome ${ }^{26,27}$. Since all described compression sutures, except the one described by Pereira et $\mathrm{al}^{22}$., penetrate the uterine cavity, the Ashermann's syndrome may be linked to the square dead space in the uterine cavity where endometrial necrosis may occur.

In summary, the U-suture technique we describe here was developed for use in emergency situations. This review of seven cases demonstrates the effectiveness of the technique over the past 32 months in controlling the atonic bleeding and its safety is shown by the absence of any associated complications. After this positive experience, we will continue to carry out uterine compression via U-suturing.

\section{References}

1. Drife J .Management of primary postpartum hemorrhage. BJOG 1997; 104: 275-7.

2. Mousa HA, Alfirevic Z. Treatment for primary postpartum haemorrhage. Cochrane Database Syst Rev 2003;(1): CD003249

3. Stafford I, Dildy GA, Clark SL, Belfort MA. Visually estimated and calculated blood loss in vaginal and cesarean delivery. Am J Obstet Gynecol 2008;199:519, e1-e7 50 AMERICAN JOURNAL OF PERINATOLOGY REPORTS/VOLUME 1 , NUMBER 12011

4. Ueland K. Maternal cardiovascular dynamics. VII. Intrapartum blood volume changes. Am J Obstet Gynecol 1976; 126:671-677

5. Hackethal A, Brueggmann D, Oehmke F, Tinneberg HR, Zygmunt MT, Muenstedt K. Uterine compression U-sutures in primary postpartum hemorrhage after cesarean section: fertility preservation with a simple and effective technique. Hum Reprod 2008;23:74-79

6. Jacobs AJ, Lockwood CJ, Barss VA. Causes and treatment of postpartum hemorrhage. Obstet Gyn 2008;16:1-3

7. Combs CA, Murphy EL, Laros RK Jr. Factors associated with postpartum hemorrhage with vaginal birth. Obstet Gynecol 1991;77:69-76

8. Dildy GA III. Postpartum hemorrhage: new management options. Clin Obstet Gynecol 2002;45:330-344

9. Prendiville W. Active versus expectant management of third stage of labour. Lancet 1998;351:1659; author reply 1660

10. Prendiville WJ, Elbourne D, McDonald S. Active versus expectant management in the third stage of labour. Cochrane Database Syst Rev 2000;(3):CD000007

11. B-Lynch C, Coker A, Lawal AH, AbuJ, CowenMJ. The BLynch surgical technique for control of massive postpartum hemorrhage: an alternative to hysterectomy? Five cases reported. $\mathrm{Br}$ j Obstet Gynaecol 1997; 104: 372-5.

12. Ghezzi F, Cromi A, Uccella S,Raio L, Bolis P, Surbek D. The Hayman technique: a simple method to treat postpartum hemorrhage. BJOG 2007; 114: 362-5.

13. Grotegut CA, Larsen FW, Jones MR, Livingston E. Erosion of a B-Lynch suture through the uterine wall: a case report. J Reprod Med 2004; 49:849-52.

14. Joshi MV, Shrivastava M. Partial ischaemic necrosis of the uterus following a uterine brace compression suture. BJOG 2004; 111: 279-80.

15. Ghodake V, Pandit S, Umbardand S. Role of modified BLynch suture in Morden day management of atonic postpartum hemorrhage. Bombay Hospital Journal 2008; 50(2): 205-211.

16. Hayman RG, Arulkumaran S, Steer PJ. Uterine compressionsutures; surgical management of postpartum hemorrhage. Obstet Gynaecol 2002; 99: 2-6.

17. Ghodake V, Pandit S, Umbardand S. Role of modified BLynch suture in Morden day management of atonic postpartum hemorrhage. Bombay Hospital Journal 2008; 50(2): 205-211.

18. Fatima N, Yasmin S, Sadaf J. Combined use of BLynch Brace suture and uterine packing in primary post partum hemorrhage: Saving life and fertility. Journal of Surgery Pakistan (International) 2010; 15(3): 144-146.

19. Khatoon A, Hasnny SF, Ansari J. B-Lynch Brace sutures for the treatment of major primary post partum hemorrhage: An experience at Abbasi 
Shaheed Hospital, Karanchi. Medical Channel 2011; 17(3): 36-38.

20. Fergusson JE, Bourgeois FJ, Underwood PB. BLynch suture for postpartum hemorrhage. Obstet Gynecol 2000;95:1020-1022.

21. Tjalma WAA, Jacquemyn Y. A uterus-saving procedure for postpartum haemorrhage. Int $\mathrm{J}$ Gynaecol Obstet 2004;86:396-397.

22. Pereira A, Nunes F, Pedroso S, Saraiva J, Retto H, Meirinho $\mathrm{M}$. Compressive uterine sutures to treat postpartum bleeding secondary to uterine atony. Obstet Gynecol 2005;106:569-572.

23. Grotegut CA, Larsen FW, Jones MR, Livingston E. Erosion of a B-Lynch suture through the uterine wall: a case report. J Reprod Med 2004;49:849852.
24. Habek D, Kulas` T, Bobic'-Vukovic' M, Selthofer R, Vujic' B, Ugljarevic' M. Successful of the B-Lynch compression suture in the management of massive postpartum haemorrhage: case reports and review. Arch Gynecol Obstet 2006;273:307-309.

25. Treloar EJ, Anderson RS, Andrews HS, Bailey JL. Uterine necrosis following B-Lynch suture for primary postpartum haemorrhage. $\mathrm{Br} \mathrm{J}$ Obstet Gynaecol 2006;113:486-488.

26. Ochoa M, Allaire A, Stitely M. Pyometria after hemostatic square suture technique. Obstet Gynecol 2002;99:506-509.

27. $\mathrm{Wu} \mathrm{HH}$, Yeh GP. Uterine cavity synechiae after hemostatic square suturing technique. Obstet Gynecol 2005;105:1176-1178. 